\title{
Language Change in Bongo Movies in Tanzania: A Reflection of Identity Deconstruction and Globalization Resulting from Socio-Cultural and Economic Transformations
}

\author{
Edwin Philemon Mwandelile \\ Educational Officer, Ubungo District in Dar es Salaam city, Tanzania Box 53714, Dar es Salam, Tanzania \\ Job Wilson Mwakapina* \\ Lecturer at Sokoine University of Agriculture (SUA) in Tanzania Box 3038, Morogoro, Tanzania
}

\begin{abstract}
After the independence of Tanganyika in1961 and its unification with Zanzibar to form Tanzania in 1964, Bongo movie artists in Tanzania have increasingly been using more English in Kiswahili movies than before. This paper sought to describe this new trend. Specifically, it highlights evidence and describes the motivations and impacts of the change. The study was conducted in Dar es Salam city involving movies acted before and after 1961 to 2013. The study involved spectators, actors and actresses, producers, directors and distributors. Data were collected through documentary review and interview methods, and were analysed descriptively and comparatively. Many factors have been realised to contribute to this change. However, they can be mainly categorised into psychological, cultural and economic factors, which all are a result of socio-cultural and economic changes which have been taking place in the country since1980s. Besides, it is revealed that the change has mainly impacted in deconstruction of Tanzanians' identity and economic gains to key Bongo movie stakeholders. The study has revealed further that the change deconstructs our identity as a nation because the country remains half-caste in film industry, since there is no clear cut between Tanzanian and Nigerian movies. Therefore, the government is urged through the National Films Censorship Board, to maintain nation's identity by inspecting, monitoring and certifying quality of movies before they are released to the market. All the substandard movies with code mixing, wrong English titles and subtitles should be monitored before they go public.
\end{abstract}

Keywords: Language change; Film industry; Identity deconstruction; Bongo movies.

(4) (†) CC BY: Creative Commons Attribution License 4.0

\section{Introduction}

Human beings as well as animals have different systems of communication. The main system used by human beings to communicate ideas, thoughts and skills to each other is language. A language is a system of arbitrary vocal symbols used in communication by a social group or a means by which a social group cooperates (Wardhaugh, 2006; Yule, 1998). When people interact with others in society at anytime and anywhere they mainly use a language. Without a language, people can communicate using other means of communication, but they can experience some troubles as they communicate. There is no any person or society without a language. The role of languages among the people in this life is very crucial. Any language, when is used for communication in any society, does not remain static; it changes. This is the case, even to the language used in films or movies.

This paper therefore, describes the new trend of mixing some English in Bongo movies and discusses motivations and impacts of the change. The paper starts by briefing the history of film industry in Tanzania, then it describes the social linguistic profile of Tanzania, and then it ventures into other parts relating to shifting language style in movies. Towards an end, the paper discusses motivations for change and the resulting impacts, and finally, conclusion and recommendations are provided.

\subsection{Brief History of Tanzania's Film Industry}

The history of film industry in Tanzania does not start with the Bongo movies ${ }^{1}$ of $2000 \mathrm{~s}$; it dates back to colonial time (pre-independence) and after independence to date. Mbura (2012) and Philemon (2013) have tried to outline the history of film industry in Tanzania. They say that few years after independence of Tanganyika in 1961 and unification of Tanganyika and Zanzibar to form Tanzania in 1964, a lot of events occurred in the country and the events brought changes in the Tanzanian film industry. These events were such as Arusha Declaration 1967, structural adjustment programmes, reform towards a free market economy, downfall of Arusha Declaration and the

\footnotetext{
${ }^{1}$ Bongo comes from the word 'ubongo' which means brain. Formerly the word was used to refer to Dar es Salaam city because it is believed that you need to use your brain to a great deal to live in the city. However, today, bongo is largely used to mean Tanzania and occasionally, East Africa. The phrase 'Bongo movies' therefore, has been used in this study to mean Tanzanian Kiswahili movies, which are locally produced for commercial purposes. Bongo Movies Industry (despite being criticized of releasing films at rapid rate and films that are half - baked or carbon copy) has changed the face of film industry in Tanzania soon after releasing films to the market Mbura,(2012)
} 
rise of private sectors. The events brought dynamism in the film industry in the country, and it is at this time when we evidenced the rise of private sectors such as privately owned television stations (Mbura, 2012).

Before independence, there were few movies that were acted in the country. Examples of these movies cited in literature are those which the then prime minister, the late Rashidi Mfaume Kawawa took role in acting; these were such as 'Chalo Amerudi, Mhogo Mchungu, Wageni Wema and Juma Matatani' (Mbura, 2012; Philemon, 2013). During the colonial time, actresses/actors from Tanganyika and Zanzibar were not free on which story to tell or to act. It was to be decided by the colonial master. After independence, Tanzanians were now free to decide what to act and which story to tell. In fact, our own film making at our own capacity can be said to have started in the late 1970s, however much efforts were vivid after the introduction of free economy in the 1980s and the establishment of privately owned televisions in 1990s (Mbura, 2012). In the country, free market introduced another variety of films in the market the Nigerian films which inspired the tendency of extreme and popularity of making films about Africa and by Africans themselves (Philemon, 2013).

The development of film industry in Tanzania can be categorised into two major periods, namely: movies which were produced in 1950s, which were entirely in Kiswahili, and the second period started after 1961 (Philemon, 2013). The movies which were produced in 1980s were such as Arusi ya Mariam, Yomba Yomba, and Mama Tumaini, and were shot in Tanzanian locations and were entirely in Kiswahili and their subtitles ${ }^{2}$ were in English. Also, Philemon shows that in the movies that were produced from 1990s up to date, there is the use of more English in a form of words, phrases, and sentences. Examples of these movies are such as Hero of the Church, Tajiri Mfupi, Unfortune Love and Big Daddy. Based on these few examples, it is seen that as time went on, from independence in 1961 to date, there is a tremendous shift in the language used in the Bongo movies. Currently, Bongo movie artists prefer to use more English titles and the content of their movies is expressed mostly often in both English and Kiswahili languages. In Tanzania today, we see an uptick of many famous and socially respected people such as businessmen and women, musicians, footballers, television and radio presenters, members of parliaments (MPs) and beauty contestants engaging in film industry in such a way that this field is now one of the respected fields and is no longer a field of the jobless people in society.

\subsection{Tanzania's Sociolinguistic Profile}

Tanzania like many other African countries has a repertoire of many indigenous languages. However, it differs from many other African countries because it has Kiswahili. Kiswahili is a lingua franca which is used as a common language between speakers of more than 120 vernacular languages which are found in the country. Kiswahili is spoken as a Second Language (L2) by a vast majority of the population and is also the national language. Kiswahili is the mother tongue of the Swahili people living along the coast and in Zanzibar as well as the younger generations of city dwellers (Brock-Utne, 2005; Sa, 2007). Many rural Tanzanians are second-language speakers; they use their local languages, which are the First Languages (L1s) for many, at home, but Kiswahili for cross-tribal communication (Gordon, 2005). Now, the relationship between English language and Kiswahili in Tanzania is that , English is the Language of Instruction(LoI) in secondary schools and higher learning institutions, and in primary schools, it is taught from grade 3-7 as a subject, while in all private primary schools, it is taught from kindergarten one (United Republic of Tanzania, 2015). Again, while English functions as the LoI in secondary schools, it is also taught as a subject.

Furthermore, Kiswahili is used in official day-to-day administration of the political, socio-cultural and economic systems of the government or nation, while English is a world language used for international communication and is highly prestigious in terms of economic and political power. Also, in Tanzania, it is used in formal situations, particularly in those which foreigners, who do not understand the national language, Kiswahili are present. In the country, both Kiswahili and English are the official languages. However, the official status of English as a second language is significantly seen in the field of education, while outside the education system, it is only spoken by a minority group, which according to Rugemalira (1990) was only a $15 \%$ of the population, though today it might be a little bit higher than that. In fact, in the wider community, English language use is limited. Its use is limited to international relations and trade, business, tourism, mass media (e.g. newspapers, Radio \& TV stations), higher courts of law, and information technologies. The limited usage of the language in public domains in itself raises questions as to whether English truly qualifies to be an official L2 in the country Nyinondi et al. (2016). Therefore, in Tanzania English is essential as it links Tanzania and the rest of the world in areas of technology, commerce and administration; at the same time, Kiswahili is very important for it makes Tanzanians maintain their identity through cultural values and heritage.

\subsection{Language Change in Bongo Movies}

Language change is the phenomenon by which permanent alterations are made in the features and the use of a language over time (Aitchison, 2001). All languages change; the change affects all areas of language use: sound system, lexical change, semantic and syntactic and morphological changes. Today, large quantities of English films are introduced in many non English native countries, more and more film titles are translated into English. For example, Heiss (2004) in German investigated on the reasons for changing the original spoken language of a film

\footnotetext{
${ }^{2}$ Subtitles are textual versions of the dialogue or commentary in films, television programs, video games, and the like, usually displayed at the bottom. They can either be a form of written translation of a dialogue in a foreign language, or a written dialogue in the same language, with or without added information to help the viewers who are deaf and hard-of-hearing or who have accent recognition problem to follow the dialogue.
} 
and found that in 1980s and 1990s the number of translated films in German increased, because at this time film producers wanted German language films to fit for global competition and more frequently they gave signs of this by using English subtitles. On the other hand, Caimi (2006) did a study on the use of subtitles to enhance Foreign Language (FL) learning. He realised that intralingual subtitling is used for L2 learning purposes which motivates learners to continue watching and encourages them to extend their intake of the language.

Similarly, in Tanzania, the translation of films from languages such as English, Hindu or Chinese into Swahili is a phenomenon which has quickly grown into a very successful business in the last couple of years (Englert, 2008). The main reason of translating these films to Kiswahili has been to connect Tanzania or East Africa to the other world. Ngunguti (2011) examined translation problems in English subtitles in few selected Bongo movies in Tanzania, and he demonstrates that translation in Tanzania is done in a wrong way because those who engage in the translation are not professional in translation, and hence they dilute quality and content of the movies. In addition, Ahangari and Amini (2012) investigated on the impact of films with and without English subtitles in Iranian English as FL learners by involving two groups of participants: the experimental group watched the film with English subtitles, but the control group watched the same film without any subtitles. At the end of the experiment, pre-test and post-test revealed that the experimental group which watched the film with English subtitles outperformed the control group of participants who watched the film without any subtitles. Thus, it can be said that subtitling is important because it is used as an additive or provides complementary information to viewers especially when is done correctly. On the use of English titles, Yin (2009) also examined the translation of English film titles in China, and found that there is the need of translating English film titles because movie titles are always the first thing that the audience come to know about new films. In addition, his study revealed that translation of film titles is the interplay of multiple complicated factors.

Apart from translating or subtitling movies, there is also an increasing use of code switching or mixing. Various studies (Carra, 2009; David and DeAlwis, 2009; Ling et al., 2012; Losch, 2007; Pai, 2005; Yusuf, 2012) have been conducted on the use of code switching in films or movies, and they highlight different reasons of why code switching is used. For example, Losch (2007) conducted a study of popular Indian cinema that uses Hindi-English code switching to examine factors that underlie code switching. Losch found that one of the reasons for code switching in popular Indian cinema is that the official languages in India are Hindi and English, which even after decolonization have remained highly influential. Also,Pai (2005) realised that in Mumbai, every child is exposed to at least four languages starting from infancy. This is the factor that causes Hindi-English code switching in film industry in India. In similar vein, Carra (2009) conducted a study on code switching between Spanish and English in American movies by examining the phenomenon of code switching and found that one of the reasons for code switching between Spanish and English language is because English is used as the language of social advancement and prestige in America. Further, Carra says that the choices of one language or the other is made as a way of showing the integration of immigrants into the receiving society.

Additionally, David and DeAlwis (2009) investigated on the factors that contribute to the use of code switching in Slumdog Millionaire movie. The scholars realised that the use of English in an Indian setting with Indian actors has allowed the movie to expand its audience from merely the Indian sub-continent to an international market. In other words, English in this case is used to enable the audience to understand the movie, while at the same time maintaining cultural setting of the story through the use of Hindi. They further point out that code switching more or less depends on the addresser, addressee, topic, setting and speech acts. Likewise, Ling et al. (2012) through the analysis of the movie Sepet demonstrate that code switching works as an essential strategy in social communication among multilingual young Malaysians. Thus, in Sepet code switching reflects communicative style and strategies among multilingual Malaysia's pluralistic society.

Other scholars like Yusuf (2012) in Kano, Nigeria and Karen (2003) consider code switching as an act of either emotional situation (love or sadness) or as mode of a speaker showing an identity or group solidarity. This is to say, Kanywood characters usually switch to English when they are in emotional state or if they want to share identity with a person or group. Yusuf argues further that code switching in Kanywood(i.e a label for movies produced by Kano actresses/actors in Nigeria) films could be described as phenomenon as opposed to Wardhaugh (2006) who asserts that, in spontaneous conversation in a movie, code switching is unconscious behaviour. Also, Yusuf shows that the characters used Hausa in their dialogue as the language of narration, assertion and interpretation, while English was used as the language of status.

Therefore, previous studies globally highlight several reasons for code switching and code mixing in movies. These studies show that code mixing and code switching in films/movies are used for several reasons: for integrating an audience which do not have a command of another language, for establishment and maintenance of social distances as an aspect of language choice, for social advancement, for expanding market from merely the actors/actresses' local area to an international market, for additive or complementary information, and for an indication of multilingual communities. Generally, a great number of studies favour the use of subtitles and code mixing or code switching. In Tanzania, there has been an abrupt shift from entirely Kiswahili movies, during preindependence in 1950s to an increasing usage or code mixing or switching, during post independence in 1961 to date. This tremendous change is a critical issue that needs researchers' attention. However, little attention, if any, has been paid to this area by researchers. Thus, this study is an attempt to describe the new trend by highlighting evidence, motivations and impacts of the change. 


\subsection{Research Questions}

The purpose of the study was to describe or document the new trend of language change in Bongo movies. To arrive to this purpose, the study had two research questions to address:

i. What are the evidence for language change and factors underlying a change in Tanzanian movies?

ii. What are the impacts of language change in Tanzanian movies to Tanzanian society?

\section{Study Methodology}

The study was conducted in Dar es Salaam city in Tanzania, and purposive sampling was used in selecting Dar es Salaam region as the study site, since the area has a big number of movie characters, directors, producers and distributors. Moreover, most film production companies are situated in Dar es Salaam, so the researchers thought that it would be easier to get relevant respondents of all categories needed for the study in Dar es Salaam, than it could be in any other regions found in the country. The study used descriptive design. The design was suitable because the data were obtained through documentary review and interview methods. Generally, the data on the factors underlying language change in Tanzanian movies and the impacts of the change were obtained through interviews, while the evidence for the change were obtained by reviewing movies or watching the selected movies.

The population of the study was categorised into two major groups: a group of objects (i.e Bongo movies); and a group of individuals (respondents). In the first group, there were Bongo movies which were acted in 1950s and after independence in 1961 to 2013. Four (4) movies acted before 1961 and 10 Bongo movies acted after 1961 were selected. The movies acted before 1961 included 'Chalo Amerudi, Mhogo Mchungu, Wageni Wema and Juma Matatani', while post-independence selected movies included 'Arusi ya Mariam, Yomba Yomba, Mama Tumaini, Kimada, Binti Yangu, Laptop, Red Valentine, Dangerous Desire Unfortune Love and Hero of the Church'. The second group involved respondents such as, Bongo movies viewers, actors/actresses, directors, distributors and producers (production experts) from Steps Entertainments, Mtitu Game 1st Quality, and Fine and Performing Art department of the University of Dar es salaam. The study involved 20 Actors and Actresses, 8 Directors and Producers, 4Distributors and 8 Spectators (Viewers). Purposive sampling technique was used in selecting group of objects (movies) and group of individuals, in order to get specific and relevant information. The researchers were assisted by some movie directors and producers in selecting movies and actors/actresses to be involved in the study. Therefore, the 14 selected movies and 40 respondents were useful in identifying evidence for language change and describing the factors and impacts of language shift in Tanzanian film industry.

Comparative analysis was used to analyse data by comparing the movies that were acted before 1961 and those which were acted from 1961 up to 2013. Similarly, the method was used to examine differences in language change according to different periods of time in Tanzanian film industry development. Descriptive method was used to analyse the data after cross-checking their validity through interviews and documentary review. After the analysis of data, the findings were presented qualitatively. The data were analysed by quick expressionist summary which involved summarizing key findings, explanation, interpretation and conclusion. Also, transcription was used particularly to Bongo movies excerpts with English subtitles, English titles, code mixing and code switching.

\section{Results and Discussion}

\subsection{Evidence of Language Change in Bongo Movies}

The first objective of the study was to describe the new trend of change by highlight evidence for language change and the factors underlying a change in Tanzanian movies. Based on the data collected, language change is reflected on the use of English subtitles, English titles, code mixing, code switching and lexical borrowing. These were not identified in pre-independence movies, but were all identified in post independence movies. Basically, these changes, code mixing and switching fall under the level of words and phrases/ sentences as morphological and syntactic changes respectively, while loanwords from English or borrowing has been described as part of lexical changes. From the data collected of 10 post independence Tanzanian movies, there was a total of 176 tokens in the data set: 28 tag switches, 102 inter-sentential switches (the most common ones), 36 intra-sentential switches, and 10 lexical borrowings. Some few excerpts /examples from post independence movies acted in 2000s are presented below. These movies are such as Red Valentine, Dangerous Desire, Deception, Unfortune Love, Hero of the Church and Laptop. In these movies, there is code mixing, code switching and lexical borrowing.

\subsubsection{Code Mixing}

Code mixing is the use of elements of two or more languages in the same word. Code mixing has been used by characters to show that they are able to converse in more than one language or they can understand both languages. That is why they can mix Kiswahili and English together. Each of the following bolded words from excerpt 1 of Dangerous Desire: ucheck, abehave, kuact and amesuspect are examples of code mixing.

\section{Excerpt 1}

Example 1 PAUL: Safi karibu ucheck nguo. [Fine, let you check clothes.] STEVE: Nimecheck lakini hakuna inayonifaa.[I've checked but there is no any suitable for me.]

Example 2 DAVIE: Yes, niamini mimi. [Believe me.] RITA: Ok, mwambie huyo abehave..... [Tell him to behave...]

Example 3 JASMIN: Wewe unataka mi kucover nafasi ya mke wako. Alafu hutaki kumwacha. Are you really serious? [You want me to cover the chance of your wife. Then you don't want to divorce her]

Example 4 JASMIN: Comfortable! Kwa kutembea na mwanaume mwingine! [For having sex with other men!] 
MIKE: Yule mwanaume siyo hadhi yako. Mimi ndiyo hadhi yako. Tunafanya hivyo ili mke

wangu asijue. Unajaribu kuact. [That man is not of your status. I'm of your status. We are doing that to blind my wife. You try to act.]

Example 5

MIKE: Mzee ndoa yangu iko kwenye mashaka mke wangu alishajua kila kitu. Amesuspect kitu. [My marriage is in bad situation Mzee, since my wife has realised something wrong. She has suspected something.]

MZEE: Hapana, tutainusuru kwa kumfanya yule kijana aigize kuwa mpenzi wa mpenzi wako.[No, we will rescue your marriage by asking that gentleman to act as the lover of your wife] Code mixing in examples 1-5 above has been done by combining Kiswahili and English, and the combination is morphologically analysed as follows:

\begin{tabular}{|c|c|c|c|}
\hline A. & $\begin{array}{ll}\text { U- } & \text { check } \\
\text { SP2SG- } & \text { check } \\
\text { You } & \text { check }\end{array}$ & B. & 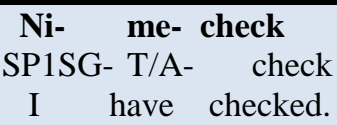 \\
\hline C. & $\begin{array}{cc}\text { A - } & \text { behave } \\
\text { SP3SG-T/A behave } \\
\text { He } & \text { behaves } \\
\end{array}$ & D. & $\begin{array}{cc}\text { Ku- } & \text { cover } \\
\text { INF- } & \text { cover } \\
\text { To } & \text { cover } \\
\end{array}$ \\
\hline E. & $\begin{array}{l}\text { Ku- act } \\
\text { INF- act } \\
\text { To act }\end{array}$ & F. & $\begin{array}{lcc}\text { A- } & \text { me } & \text { suspect } \\
\text { SP3SG- } & \text { T/A } & \text { suspect } \\
\text { She } & \text { has } & \text { suspected }\end{array}$ \\
\hline
\end{tabular}

\subsubsection{Code Switching}

Code switching happens when speakers alternate languages as they speak within an utterance or discourse. In the analysed data, the tokens for code switching were divided into three categories or types, as defined by Poplack (1978/1981): Tag switches, intersentential and intrasentential switches. All the three types of code switching were revealed in the post-independence analysed movies. First, tag switching is related to the inclusion of a tag or a tag phrase or a word from one language to the utterance of other language (e.g. you know, I mean, right, anyway, ok). This type of code switching is very simple and does not involve a great command of both languages since there is a minimum risk of violating grammatical rules. For example, excerpt 2 from the movie of Laptop, words in bold indicate tag switch:

\section{Excerpt2}

Example 6 RITA: Mama vipi kuhusu hela ya graduation? [How about money for graduation my mom?] MAMA RITA: Aaah! Samahani mwanangu nilisahau kabisa. Lakini si bado miezi minne.[I'm very sorry my daughter I did forget, but I think four months have remained.]

RITA: Aaaah! Mama kila siku unasahau.[Everyday you forget my mom.]

MAMA RITA: Anyway! goja nikacheck bajeti. Naona bajeti yangu haikubali. Ok!

Nitakuletea shuleni nikitoka Benki.[Let me check my budget. My budget is not enough. I will bring you money at school after returning from Bank.]

The second type and the most complex type of code switching is the intrasentential one. It is a switch to another language that occurs within a sentence or phrase. It is the interesting since its occurrence may be avoided by all except the most fluent bilingual (Romaine, 1985). The complexity of this type of switching is explained by high probability of violation of syntactic rules as well as the requirement of a great knowledge of both grammars and how they map onto each other. On the data set, however, this was the second most frequent one: 36 out of 166 switches were intrasentential. For example from Dangerous Desire a character called Japhet says to his wife Joyce 'Asante sana my darling'. [Thank you very much ...]. This has occurred within a sentence. This is also seen in excerpt 3 of the movie of Red Valentine:

\section{Exerpt 3}

Example 7 NICOLOUS: Unaniambia nini? [What are you telling me?] VIVIAN: Nicolous, basi calm down. Siyo kila kitu inabidi ufoke, utumie hasira kaa chini tuongee.[Nicolous, calm down. Do not quarrel on everything, calm down, let us sit down and talk]

The third type of code switching is the intersentential switching, which occours outside a phrase or sentence level. For instance, in the movies of Kimada, there are perfect examples of intersentential switching. There are both that which occours outside a phrase and sentence level (see Excerpt 4 ).

\section{Excerpt 4}

Example 8 JASMIN: Wewe unataka mi kucover nafasi ya mke wako. Alafu hutaki kumwacha. Are you really serious?[You want me to cover the position of your wife. Then you don't want to divorce her.] MIKE: Ninachotaka mimi nifanye, I want you to be comfortable. [What I want to do,] JASMIN: Comfortable! Kwa kutembea na mwanaume mwingine![For having sex with another man!]

\subsubsection{Borrowing}

Lexical borrowing is the incorporation of words from one language in another language or in the recipient language. From the data of the study, there are cultural and core borrowing that have been revealed. According to Myers-Scotton (2006), borrowing can roughly be divided into two categories: cultural and core borrowing. Cultural borrowing is a process of taking words that fill gaps in the recipient language's store of words. They stand for objects or concepts new to the language's culture. For example, cultural borrowing is seen when the movie 
characters do not have equivalents in Kiswahili like Hospitali comes from English word Hospital, Benki from English word Bank, dijitali from English word digital. On the other hand, core borrowing refers to a word(s) that duplicate elements that the recipient language already has it in its store. Core borrowing occurs due to cultural pressure: when two languages are spoken in the same community, but one language prevails in most public discourse and certainly in all status-raising discourse, and it becomes the recipient language in borrowing and will even replace its own words from the dominant language. Core borrowing includes loanwords that are adopted despite the fact that a word for the concepts already exists in the recipient language (Myers-Scotton, 2006). Examples of these words which are a result of core borrowing are like stori instead of using hadithi, Kompyuta insteady of Ngamizi in Kiswahili language. These are found in the movie of Laptop and in Red Valentine in Excerpt 6 and Excerpt 7 respectively.

Excerpt 5

Example 9 MWANDISHI: Hapa ni Kiu Publishers. Na mimi ni Mwandishi wa habari. tuna stori yako hapa.[Here is Kiu Publishers. I'm the journalist. We have your story.]

RITA: Stori gani? [What is it?]

Example 10 RITA : Aaaah! Mama kila siku unasahau. [Everyday you forget my mother.]bMAMA RITA: Anyway, Ngoja nikacheck bajeti. Naona bajeti yangu haikubali. Ok nitakuletea shuleni nikitoka Benki. [Let me check my budget. My budget is not enough. I will bring you money at school after returning from Bank]

Excerpt 6

Example 11 NICOLOUS: Unaniambia nini? [What are you telling me?] VIVIAN: Nicolous, basi calm down. Siyo kila kitu inabidi ufoke, [...] Mimi nashauri tu mume wangu twende hospitalini tukapime afya zetu.[Nicolous, calm down. Do not quarrel on everything, [...] I advise you my husband to go to hospital for health check up]

Here, the distinction between code switching and borrowing is that where there is no integration of the word or clause into the language spoken in code switching there is morphological and phonological integration in borrowing (Grosjean, 1982). For example, morphologically, the word in Kiswahili kozi comes from English word course, phonologically in Kiswahili $(/ \mathrm{k} \mathrm{z} /)$ comes from $(/ \mathrm{k}: \mathrm{s} /)$ in English. It is seen several times (reoccurrence) in the data collected (reoccurrence) and it is almost acceptable in recipient language like the words kozi, semista, bajeti, stori as it was revealed in the movies while in code switching there is no reoccurrence and acceptability in the society. Lexical borrowing is integrated to adopt the form and structure of recipient language which is Kiswahili.

\subsection{Factors Underlying Language Change in Tanzanian Movies}

The second objective of the study was to analyse the factors underlying the change from entirely Kiswahili movies to a new trend of mixing English in a Kiswahili movie. To make that, the researchers used interviews to get views from respondents on the factors that influence the use of English subtitles, English titles, code mixing and code switching. The respondents gave more than 20 factors, but during analysis it was realised that some were just repeating the same already said factors in a different language. The researchers, therefore, came up with 13 factors as indicated in the chart.

Cultural change is one of the main factors that lead to language change in Tanzanian movies. Findings of this study show that the use of code mixing and code switching and English subtitles in Tanzanian movies is due to the change in culture. During 1967 to 1989, the Ujamaa socialism, socialist practices limited people's access to foreign music, movies and cultures, while after the fall of ujamaa socialism, Tanzanians were then exposed to different foreign cultures (Perullo, 2007). As a result, Bongo movies as well as Bongo flava musicians started embracing English as a co-language in movies, as well as speaking styles, dressing styles and many others from outside the country. As seen from the chart, majority of participants said that mixing English in Bongo movies is a sign that Tanzanians have changed generally their behaviour and culture.

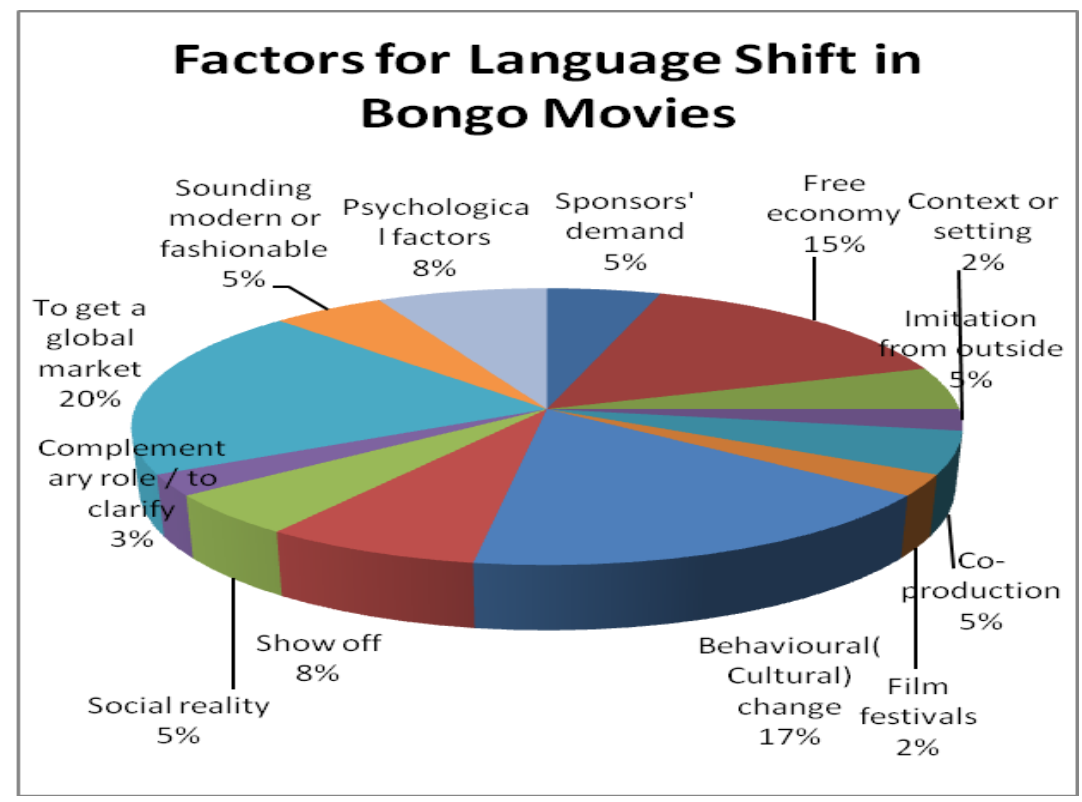


As seen from the chart, it has been realized that among the 40participants, majority of participants said search for an international market plays a big role in language change in Tanzanian movies. They see that among the main factors for the use of English subtitles is to capture market for local and external audience. The movie characters, directors, producers and distributors use English subtitles for the aim of suiting into international market. The strategy helps distributors to sell their movies to non Kiswahili speakers outside Tanzania. This is in line with the findings of David and DeAlwis (2009) who realised that English was used in Indian movies to reach an international market. The respondents insisted that since English is a global language and is the business language, actors/actresses find themselves being forced to mix languages so that the people who do not know Kiswahili may also understand. For example, some respondents cited examples of movies like Dangerous Desire and Red Valentine that have English subtitles to make others who do not have a command of Kiswahili understand the movies. Other two respondents at different times gave the same reason, one said that... subtitling is demanded by world satellite like DSTV broadcast in South Africa which needs movies to be subtitled for foreigners to view; and the other said '... Zuku in Kenya wants movies to be subtitled in English so as to be understood by others.

Another factor is sponsors' need. It was realized that one of the reasons for use of subtitles is the demand from the sponsors and distributors who decide to sponsor the production of the movie, and not the will of the actors or actresses. The producers who are sponsors force their movies to have subtitles in order to find new audience beyond Tanzania. In 1980s for example, the films of Arusi ya Mariam and Mama Tumaini produced by Tanzania Film Company, were sponsored by foreigners who demanded the movies to be subtitled in English so as to be understood by their mother countries. For that matter, the sponsors conditioned those movies to be subtitled in English language. Connected to this is that sponsors of movies want their movies to win awards in the International Film Festivals (IFFs). IFF demands that movies that are to be considered for IFF competition awards must have English subtitles so as to be understood by many people. Due to this demand, many sponsors always force Bongo movies to be subtitled in English language. During data collection, some respondents said that many sponsors of movies force to subtitle movies in English to win judges during IFF competition awards. This is to say, subtitles help the international judges to give fair judgment in the IFF competition. Thus, language change in the Bongo movies in Tanzania is a response to sponsors demand which is intrinsically motivated by IFF awards.

Co- production was also highlighted by some participants. The movies which have been produced with both Tanzanian and an outsider actor/actress have English subtitles, code mixing, code switching and most of them have English titles. This study revealed that in 2006 for example, Mtitu Game took a step further to relate between Nollywood (film industry in Nigeria) and Bongowood and produced Dar 2 Lagos. It is a movie which was shot in Nigeria and Tanzania involving both Tanzanian and Nigerian characters. This is the first Tanzanian film to be shot in Nigeria with real Nollywood movie characters. In the movie, there are code mixing, switching and subtitles. It is seen that the characters from Nigeria use English which they are exposed to because they do not know Kiswahili, while Tanzanian characters use Kiswahili which they are much fluent. Thus, in this kind of a movie, code mixing, code switching, English subtitles and English titles are inevitable. Also, it is reflected from the study that language change in movies is due to social reality (Multilingual situation). In Tanzania, it is very common to see many people switching codes while conversing. The situation is common to be seen in mass media, in schools, buses, telephone conversation, in markets, parliamentary assembly hall, and in many other areas. As such, it is no wonder to see characters in movies also switch or mix codes. Thus, code mixing or code switching in Bongo movies reflects daily life practices of the Tanzanian society.

Likewise, it was reflected from the study that English is used in Bongo movies as an act of show off. Some participants indicated that language change in the movies is due to a tendency of show off. Participants indicated that actors/actresses use code switching particularly from Kiswahili to English, to show that they have gone to school or are educated. One interviewee went far posing a question that, why don't they code mix from Kiswahili to their vernacular languages, which are the languages they are much more conversant, like Kimakonde, Kizaramo, Kizigua or Kikinga? We always see them switching to English, why? It is just a show off because their vernacular languages are not prestigious. Formerly, in the country, those engaging in Bongo movies or Bongo flava music were considered illiterate and jobless. To camouflage, many artists tend to mix some English in their Kiswahili movies, because using English in Tanzania is prestigious. The Tanzanian public associates English language with better education and quality life because of the economic opportunity that comes with the ability to use the language. This finding corroborates with Carra (2009) who found that one of the reasons for code switching from Spanish to English language in movies is because English is used as the language of social advancement and prestige in America. In this respect, movie characters, even those who do not know English well tend to switch to English or to mix some words of English in their Kiswahili utterances in order to show prestige or to indicate that they are capable of speaking English. They impliedly convey massage to the public that their educational level as well as quality of life is not low, which might not be the case. The other interviewed participants said:

in the previous years, acting or engaging in film industry in Tanzania was taken as a lack of opportunity to earn a living in the sense that actors and actresses were considered as non educated people, so they tend to mix some English to tell the community that they have gone to school.

Additionally, the other factor that the Bongo movie spectators gave is a desire to sound modern or fashionable. It has been realised from the study that many Bongo movie artists code mix or switching when they execute events in a movie scene because they want to be seen modern or fashionable by people or watchers. In respect of this, characters in Bongo movie sometime mix languages because of their desire to show the public that they are modernized. One of the movie spectator interviewed in Dar salaam said: 
these artists because are famous, they do not want switching or mixing Kiswahili with their indigenous languages like Kingoni, Kizigua, Kikwere or Kichaga since doing that makes them think, they sound traditional, so they will always strive to show that they are modern by mixing some English because English is the global language for trade and modernization.

A large number of participants said many movie characters in Tanzania mix English in Bongo movies because of the free market economy. The free market economy which occurred in Tanzania from 1980s resulted in the raise of many private sectors in 1990s. For example, at this time, in the country we evidenced the raise of private radio and TV stations as well as private secondary schools and the English medium primary schools. These had a great contribution to the development of film industry in Tanzania. Notably, Independent Television (ITV) started supporting the making of local TV drama for its own broadcast, and the producer and actors involved in that process learned through apprenticeship on how to make videos (Mbura, 2012). Again, due to the increase of private schools and English language learning centres, Bongo movies and Bongo flava artists could go and learn English in these schools and centres. Eventually, when they acted, they would tend to mix English in a Kiswahili movie, which was not a common tendency before.

Also, free economy made Bongo movies artists to imitate films from other countries. Philemon (2013) indicates that the consumption of Nigerian films was still at its peak in Tanzania between 2003 and 2006. So, a lot of the produced movies at that time were seen to have blended features from Bollywood( the Indian Hindi- language film industry ) and Nollywood. Thus, it is realised that the use of English titles is the product of imitation from Nigerian movies so as to capture the local and external audience. 'The title of the movie must above all be memorable and if possible convey an accurate impression of the movie's content'. This was said by the majority of Tanzanian movie distributors. However, the strategy of using English titles in Tanzanian movies is popular than once it was, but still it gets the nod when distributors distribute films to the public in Tanzania where majority Tanzanians have a command of Kiswahili language.

Lastly, some participants said Tanzanian Bongo movies artists always tend to switch to English or code mixing when they are in state of emotions (psychological factors). They said that Bongo movies artists prefer to express their love or sadness through English language than in Kiswahili or vernacular languages like Kizaramo, Kisukuma or Kisafwa in which they may be much more fluent. This is also evident in Dangerous Desire movie where we see Japhet speaking in Kiswahili and when he wants to tell his wife that he loves her, he switches to English and also the wife in the same way she responds in English, 'I love you too'. It has been realised from the study that code mixing and switching are much used when characters want to expression love or emotions. This is because love is not expressed openly in African culture. This finding is supported by the finding of Yusuf (2012) who found the same that code switching in Hausa film industry in Nigeria is mainly due to emotional situation.

\subsection{Impacts of Language Change in Bongo Movies}

There are mainly six (6) positive and negative impacts realised from the study and are hereby discussed below:

\subsubsection{Economic Gains}

It has been realised that economic gain is one of the positive outcomes of the use of some English in Bongo movies. It is shown that subtitling is good because it helps Bongo movies to cross borders to other African countries such as Congo, Rwanda, Kenya, Uganda and even others away from Africa. As a result, when the movies are bought in these countries, they provide economic gains particularly to key stakeholders such as the producers, distributors, directors, actors and actresses. This finding is supported by Heiss (2004) and David with his colleague David and DeAlwis (2009) who, at different times, realised that in German between 1980s and 1990s original spoken languages of films were translated to English or other languages to secure an international market for economic gains, and that the use of English in a Slumdog Millionaire movie that was co-directed by a British and an Indian in an Indian setting with Indian actors allowed the movie to expand its audience by capturing an international market respectively.

\subsubsection{Helps in Language Learning}

It has been realised that subtitling, code switching and mixing help in language learning. The respondents of the study said that mixing English in Bongo movies helps many people from other countries to learn Kiswahili as well as many Tanzanians who do not know English through watching bongo movies they can pick up or acquire some English words or utterances. This finding is in line with Ahangari and Amini (2012) who did a study to investigate the impact of films with and without English subtitles on Iranian FL learners of lexical phrases. At the end of their experiment, they came to realise that participants who watched the film with subtitles outperformed the participants who watched the same film but without any subtitles. Therefore, Bongo movies with subtitles, code switching and mixing can be effective tools in enhancing L2 or FL positive teaching and learning environments in Tanzania and in other countries for learners with visual problems, learners who are deaf and those with hard-of-hearing, only if, translation of subtitles is done by experts of translation.

\subsubsection{Additive or Complementary Role}

Participants of the study during interviews said that subtitling or code switching is very important in movies particularly when is done correctly because it helps to clarify or give more information on actions or words of which watchers might not understand what it means in the original language. Sometimes actresses/ actors may use non- 
verbal signal of which without subtitles, those who are watching the movie might not understand what it means. This corroborates with Dastjerd and Rahekhonda (2010) who found that it is good to use subtitling to add information. This is to say, because of paraphrasing which the subtitler or translator may do, the spectators may get the meaning across of some things that they might not understand from the original language. In this regard, subtitling helps in performing an additive or complementing role.

\subsubsection{Confuses and Leaves Viewers in Dilemma}

Confusion is one of the negative impacts for language change in Tanzanian movies. It was realised that language change in Tanzanian movies leads to the distortion of message. It was revealed that spectators who know both languages, the original language of the movie and the target language (the language into which a speech is translated) or those who know only the target language (i.e. English)end into semantic confusion because subtitling or translations that Tanzanians do in Bongo movies from Kiswahili to English are full of mistakes and in most cases are wrong, because as revealed by Ngunguti (2011) they are wrong because translation is done by individuals who are not experts of translation. As a result, a wrong translation taints the content of the movie, while at the same time; it waters down quality and the value of Bongo movies. Therefore, spectators can get confused because they may find that translations do not match with either the speech or actions that actors/actresses do. Also, spectators who know both languages always are left in a dilemma, while those who know only the target language get confused semantically. 'Spectators are left in dilemma as to which language to follow 'particularly those who are fluent in both languages. Should they follow the spoken original language or target language? This question was probed by one interviewee. It was realised that due to that situation, viewers get confused and are left in dilemma on which language to follow. However, the decision of whether to follow the original language or the translation of the movie or the target language remains on the decisions of the viewers themselves. Of course, sometime making decisions as to which one to follow may be a very big conundrum to spectators who are fluent in both languages.

\subsubsection{Frustrates Spectators}

It was realised that language change in movies frustrates viewers because what you expect to be seen as a subtitle becomes a paraphrase or a different thing from the original language of the movie. Usually, when a movie or TV program is subtitled, the subtitler watches the picture and listens to the audio sentence by sentence. The subtitler may or may not have access to a written script of the dialogue, especially in commercial subtitles; the subtitler often interprets what it meant, rather than how it is said. In such a situation, there will be mismatch between what is said in original language of the movie and on the subtitle. Many of the participants particularly viewers who knew both languages, Kiswahili and English, did not appreciate this; they said it is frustrating to the extent of desiring no more to watch for such movies. In fact, spoken language may contain verbal padding or cultural implied meanings which, if they are not well adapted in the written subtitles, viewers will always get frustrated. However, it was realised further that sometimes, it is inevitable for translators/ subtitlers to avoid that because a subtitler is required to condense the dialogue in order to achieve an acceptable reading speed or to match the speed of the spoken dialogue of the original language and the written dialogue of the target language. In this context, the purpose or theme becomes far more important than form.

\subsubsection{Identity Deconstruction}

Deconstruction of Tanzanian film industry identity is another negative outcome of language change in Tanzanian movies. The findings from the study showed that, due to imitation from outside, the film industry of Tanzania has no identity of its own. There is no identity that could be identified for Tanzanian film industry outside the country and even within the country because of mixing Kiswahili and English in the movies. Identity at its core is the means by which we actually choose to identify ourselves and by which others recognize us. Language and identity are like two sides of the same coin. Language provides the framework for identity and association that might otherwise not exist. When one changes a language, the identity also changes to diverge or converge oneself from or into a group or community, hence code-switching can be used as a way of showing bond or distancing oneself from speakers of a language or code. Construction of identity is, therefore, a public process that involves identity announcement, made by the individual claiming an identity and the identity placement, made by others endorsing the claimed identity (Stone, 1981).

This study realised that Bongo movies continue to play the major role of identity deconstruction. People from outside cannot differentiate between Tanzanian and Nigerian movies because there is no clear cut identity of the two countries. Thus, most movies have consciously and unconsciously perpetuated such identity deconstruction by using English and Kiswahili instead of using only Kiswahili. Mixing English and Kiswahili often leads our country to remain half caste in film industry. There is no identity of Tanzanian film industry at all. From the study, it was revealed that if the process of film production does not go hand in hand with conscious raising on producers and scriptwriters on the need to use their creative artistic work as an arena for maintaining our identity and values, Bongo movies together with Bongo flava industry will continue to reinforce identity deconstruction.

\section{Conclusion and Recommendations}

Language used in Bongo movies in Tanzania after independence has changed tremendously. Today, English subtitles, English titles, code mixing and switching have been more common in Bongo movies than before. This change has been triggered by many factors, such as free market, social reality, sponsors' demands, modernity, co- 
production, international markets and psychological factors. All these have been a result of socio-cultural and economic changes which have been taking place in the country since1980s. The shift of style to mixing some English has mainly impacted in deconstruction of Tanzanians' identity and economic gains to key stakeholders. What has been described as language change in this paper is not a complete change, but a gradual transition, which indicates that one day we might have Bongo movies which are completely in English. It should be noted that, language change particularly subtitling in movies is not a bad thing. However, it needs to be done by experts to avoid watering down the content, quality and values of Tanzanian movies. If local productions in the future continue to retain the culture of using English titles, code mixing, code switching and wrong English subtitles, it will not be possible for Tanzanian film industry to venture into international platform in the USA and Europe.

Therefore, the study recommends first, the government to insist the Directorates of Culture Development and Sports Development, in collaboration with the National Films Censorship Board of Tanzania and the National Arts of Council of Tanzania, abbreviated in Kiswahili as BASATA, to be aggressive at inspecting and monitoring the film industry of Tanzania by maintaining Tanzanian identity and certifying the quality of movies before they are released to the market. This is because it is not the Bongo movie artists or Bongo flava artists whom the Tanzanian society has held responsible for moral standards of society but priests. However, the roles of these artists in modern society are far more influential. They provide what are called role models in which any case young people take up how they dress, speak and internalize their expressions and values they carry, so if they are not monitored well, young generations through watching movies may end up copying identities and cultures which are not of the Tanzanians. Secondly, there should be quality criteria to adhere to at all stages of the movie production. All the substandard movies with code mixing, code switching, wrong English titles and subtitles should be monitored. Furthermore, the government in cooperation with private companies should invest in film production industry by opening up more colleges that will offer short and long term courses in arts and culture in general and in movie production in particular. Also, Bongo movie customers or spectators in Tanzania are urged to create a habit of giving feedback whether positive or negative to the producers, actors and actresses with regard to the quality of the movies. Lastly, given the role of English in globalization and development, if it is necessary to subtitle, it should be done by experts of translation. This will help learners of spoken dialogue as a L2 or FL, visual learners, learners who are deaf or those with hard-of-hearing and language teachers to use Bongo movies as tools to facilitate L2 or FL teaching and learning.

\section{References}

Ahangari, S. and Amini, S. M. (2012). The impact of films with and without subtitles on iranian english as foreign language learners' mastery of lexical phrases. American Journal of Scientific Research, 69(3): 68-80.

Aitchison, J. (2001). Language change, Progress or decay. 3rd edn: Cambridge University Press: Cambridge.

Brock-Utne, B. (2005). The continued battle over kiswahili as the language of instruction in tanzania. Languages of instruction for african emancipation. Mkuti Na Nyota: Dar es Salaam.

Caimi, A. (2006). Audiovisual translation and language learning: The promotion of intralingual subtitles. Journal of Specialised Translation, (6): 85-98. Available: http://www.jostrans.org/issue06/art_caimi.php

Carra, N. J. (2009). The presence of spanish in american movies and television show, dubbing and subtitling strategies. Universidad Pablo de Olavide: Servilla.

Dastjerd, H. V. and Rahekhonda, R. (2010). Expansion in subtittling: The case of three English films with Persian subtitles. Journal of Language and Translation, 11(1): 7-27.

David, M. K. and DeAlwis, C. (2009). Code switching as a communicative strategy for international audience comprehensibility in 'slumdog milionaire", language and societynewsletter. Available: http//www.crisaps.org/newletter/winter2012/David.pdf

Englert, B. (2008). Kuchanganyachanganya - topic and language choices in tanzanian youth culture. Journal of African Cultural Studies, 20(1): 45-55.

Gordon, R. G. J. (2005). Ethnologue: languages of the world Dallas. TX: SIL International.

Grosjean, F. (1982). Life with two languages. Cambridge University Press: Cambridge, MA.

Heiss, C. (2004). Dubbing multilingual film, A new challenge. Meta Translator's Journal, 49(1): 208-20.

Karen, K. Y. C. (2003). Code-switching for a purpose, Focus on preschool malaysian children. Multilingua, 22(1): 59-77.

Ling, L. Y., Jin, N. Y., Tong, C. S. and Tarmizi, M. A. A. (2012). Code switching in sepet, Unveiling malaysians' communicative styles. British Journal of Arts and Social Sciences, 6(2): 2049 - 9578.

Losch, E. (2007). The construction of social distance through code switching an exemplary analysis for popular indian cinema. Technical University of Chemnitz: New Delhi.

Mbura, I. (2012). Tanzania film industry development and challenges in tanzania after 50 years of independence. DUP: Dar es Salaam.

Myers-Scotton, C. (2006). Multiple voices, An introduction to bilingualism. Blackwell: Malden, MA.

Ngunguti, M. A. (2011). Problems of kiswahili-english translations as reflected in English subtitles in selected tanzanian kiswahili movies, Unpublished dissertation. University of Dar es Salaam.

Nyinondi, O. S., Mhandeni, A. S. and Mohamed, H. S. (2016). The use of communicative language teaching approach in the teaching of communication skills courses in Tanzanian universities. International Journal of Research Studies in Language Learning, 6(3): 89-99. 
Pai, P., 2005. "Multilingualism, Multilingual And Education, Case study of mumbai city in cohen, James, Macallister, Kara, T. Rolstad, Kellie, Jeff." In Proceedings of the 4th International Symposium on Bilingualism, Somerville, MA, Cascadilla Press.

Perullo, A. (2007). Here's a little something local. An early History of Hip Hop in Daries.

Philemon, E. (2013). Language change in tanzania film industry. Ma dissertation. The University of Dodoma: Tanzania.

Poplack, S. (1978/1981). Syntactic structure and social function of code switching, in r.P. Duran, (edn.), latino discourse and communicative behaviour. Ablex Publishing Co-operation: New Jersey. 169-84.

Romaine, S. (1985). Bilingualism. Blackwell: US.

Rugemalira, J. M. (1990). The communication skills unit and the language problem at the university of dar essalaam. In c. M. Rubagumya (ed), language in education in africa, A tanzanian perspective. Multilingual Matters: Clevedon. 105-22.

Sa, E. (2007). Language policy for education and development in tanzania. Swarthmore.

Stone, G. (1981). Appearance and the self, A slightly revised version. In g. Stone \& h. A.

United Republic of Tanzania (2015). Education and training policy. Ministry of Education and Vocational Training: Dar es Salaam.

Wardhaugh, R. (2006). An introduction to sociolinguistics 5th edn: Blackwell Publishers Ltd: USA.

Yin, L. (2009). On the translation of English movie titles. Asian Social Sciences, 5(3): 171-73.

Yule, G. (1998). The study of language. Cambridge UP: Cambridge.

Yusuf, C. I. (2012). Hausa-english code-switching in kanywood films. International Journal of Linguistics, 4(2): 8796. 